Department of

Economics and Finance CEECs, Russia and the UK

March 2010 


\title{
Stock Market Integration Between three CEECs, Russia And The UK
}

\author{
Guglielmo Maria Caporale* and Nicola Spagnolo \\ Centre for Empirical Finance, Brunel University, London, UK
}

February 19, 2010

\begin{abstract}
This paper estimates a tri-variate VAR-GARCH(1,1)-in-mean model to examine linkages between the stock markets of three Central and Eastern European countries (CEECs), specifically the Czech Republic, Hungary, and Poland, and both the UK and Russia. The adopted framework allows to analyse interdependence by estimating volatility spillovers, and also contagion by testing for possible shifts in the transmission of volatility following the introduction of the euro and EU accession. Further evidence on possible changes in the transmission mechanism (namely, on whether there is contagion) can be obtained by examining the conditional correlations implied by the estimated model over different time periods. The empirical findings suggest that there is significant co-movement (interdependence) of these CEEC markets with both the Russian and the UK ones. Furthermore, whilst the introduction of the euro has had mixed effects, EU accession has resulted in an increase in volatility spillovers between the three CEECs considered and the UK (contagion).
\end{abstract}

Keywords: Central and Eastern European countries (CEECs), volatility spillovers, interdependence, contagion, VAR-GARCH-in-mean model

JEL Classification: C32, F36, G15.

${ }^{*}$ We would like to thank two anonymous referees for very useful comments and suggestions. Corresponding author: Professor Guglielmo Maria Caporale, Centre for Empirical Finance, Brunel University, West London, UB8 3PH, UK. Tel.: +44 (0)1895 266713. Fax: +44 (0)1895 269770. E-mail: GuglielmoMaria.Caporale@brunel.ac.uk 


\section{Introduction}

The degree of integration of international financial markets is a topic often investigated in the literature given its importance for portfolio management strategies, strong links implying limited diversification benefits for international investors. Financial stability can also be affected, and therefore policy-makers are also very interested in financial integration. A number of measures have been used, such as cross-correlations (see, e.g., Koedijk et al., 2002 and Longin and Solnik, 1995), volatility spillovers (see, e.g., Engle and Susmel, 1993, and Ng, 2000) etc., as well as a variety of econometric approaches, including GARCH modelling (see, e.g., Hamao et al., 1990 and Bekaert et al., 2005), and cointegration analysis (see, e.g., Kasa, 1992 and Richards, 1995). More recently, Forbes and Rigobon (2002) have distinguished between interdependence, i.e. existing cross-market linkages, and contagion, which in their definition only occurs if such linkages become stronger in crisis periods (see also Caporale et al., 2005).

Most empirical studies have focused in the past on developed markets (see, e.g., Francis and Leachman, 1998). However, as a result of the process of EU enlargement, more research efforts have been spent in recent years to analyse the progress made in the Central and Eastern European countries (CEECs) towards financial integration with the developed EU member states, for a variety of reasons. In particular, efficient financial integration is crucial both for the accession process itself and the long-term performance of the EU as a whole. Further, the financial crises affecting other emerging markets in Asia and Latin America in the 1990s had led to higher foreign investment in the CEECs, and therefore the question has arisen whether closer financial integration with the developed EU countries would reduce the benefits of portfolio diversification.

Following the removal of restrictions on capital flows and the opening up to foreign investors, the creation of appropriate corporate governance structures and the establishment of ownership rights, both market capitalisation and daily trading volumes increased rapidly in the CEECs during the transition (see Egert and Kocenda, 2007). They also acquired weak market efficiency (see Bohl et al., 2006). Moreover, trade links with the EU also became considerably stronger, leading to further economic integration by the time of the formal accession of the CEECs to the EU in May 2004 (see IMF, 2005). However, the size of equity markets in these countries is still relatively small compared with developed ones, and they tend to exhibit higher volatility, possibly because of their sensitivity even to relatively small portfolio adjustments, as argued by Egert and Kocenda (2007).

The existing evidence on their financial integration is mixed. Linne (1998) found linkages 
between the CEEC markets themselves, but not with the developed countries. No relationship with the US or Germany was found by Gilmore and McManus (2002, 2003) either, and no convergence of the CEEC markets towards the developed ones was detected by Serwa and Bohl (2003). By contrast, MacDonald (2001) reported long-run co-movement with some developed markets (US, UK and Germany), and Syriopoulos (2007) also concluded that the CEEC markets are more strongly linked with the mature economies than amongst themselves. Jochum et al. (1999) reported that the Russian 1997-1998 crisis affected the degree of integration between financial markets in Poland, Hungary and the Czech Republic, these markets ceasing to be linked to both the Russian and US ones after the crisis. Verchenko (2000) also did not detect co-movement with the Russian market.

Among studies focusing on short-run linkages, Scheicher (2001) presented evidence that regional (rather than global) factors are the main driving force of volatility in the three main CEECs. Gelos and Sahay (2000) and Chelley-Steeley (2005) found increasing correlations with the developed markets. Long-run co-movement is analysed in other papers. Serwa and Bohl (2005) focused on contagion, and reported that the transition economies of Central and Eastern Europe are particularly prone to it. Using high-frequency intraday data and cointegration, VAR and Granger causality techniques, Egert and Kocenda (2007) found no significant co-movement between the markets of Hungary, Poland and the Czech Republic or interdependence with Western European stock markets. However, there appear to be short-term spillovers both in returns and in their volatility. This suggests that portfolio diversification might still be effective in this case. Cappiello et al. (2006) examined the constancy of correlations by means of a regression quantile approach, and reported that the degree of integration of the new EU member states with the euro zone has increased in the run-up to EU accession. Using a smooth transition correlation model to estimate conditional correlations for weekly data, Savva and Aslanidis (2009) also found that the Czech, Slovenian and Polish markets have become more correlated to the Euro-zone from 1997 to 2008, and that this reflects EU-related rather than global developments.

Other studies point out that linkages between equity markets might be time-varying. For instance, Voronkova (2004) was able to detect links with the developed EU economies when allowing for structural change. Gilmore et al. (2008) used dynamic cointegration and principal components to analyse both short- and long-run co-movement between Hungary, Poland and the Czech Republic and the developed EU countries. They showed that, whilst a static approach would indicate only a low degree of long-run co-movement, dynamic analyses reveal intermittent periods of cointegration. Overall, no evidence can be found that EU accession has resulted in significant convergence between equity markets that would reduce 
the benefits of portfolio diversification. Extending their work, Harrison and Moore (2009) investigated co-movement between the CEEC markets on one side and the UK and German ones on the other allowing for non-linear cointegration as well as time variation. They found no evidence of cointegration for the full sample, but did conclude that co-movement between the Czech Republic, Hungary, Poland, Romania and Western Europe is increasing over time. As for the driving forces of market integration, Hanousek et al. (2009) and Hanousek and Kocenda (2009) showed that macroeconomic announcements originating from mature markets affect strongly real-time interactions of new EU markets. Finally, Mihaljek (2009) analysed the spread of the current financial crisis to the CEECs using BIS data, and argued that foreign bank ownership meant only limited reversals in cross-border financial flows.

Of the studies on the CEECs reviewed above, very few use a GARCH modelling approach (these include Egert and Kocenda, 2007, and Hanousek and Kocenda, 2009, as well as Savva and Aslanidis, 2009, the latter estimating a smooth transition conditional correlation (STCCGARCH) model), and/or make a clear distinction between contagion and interdependence (see Serwa and Bohl, 2005, and Egert and Kocenda, 2007). The present paper estimates instead a tri-variate VAR-GARCH(1,1)-in-mean model to examine linkages between the equity markets of three Central and Eastern European countries (CEECs), namely the Czech Republic, Hungary, and Poland, and both the UK and Russia. These three particular CEECs are chosen as the ones having the highest market capitalisation in the region. Similarly, the UK is a natural benchmark for the CEECs among European developed markets owing to its high market capitalisation and resulting information flow. Russia, on the other hand, represents an emerging benchmark sharing many common features with the CEECs (such as the creation of a stock market after mass privatisation as an outlet to trade stocks of newly privatised firms, weak regulation for a considerable period of time, etc.). The adopted framework allows to analyse interdependence by estimating volatility spillovers, and also contagion by testing for possible shifts in the transmission of volatility following the introduction of the euro and EU accession. Further evidence on possible changes in the transmission mechanism (namely, on whether there is contagion) can be obtained by examining the conditional correlations implied by the estimated model over different time periods. The layout of the paper is the following. Section 2 outlines the econometric modelling approach. Section 3 describes the data and presents the empirical findings. Section 4 summarises the main findings and offers some concluding remarks. 


\section{The model}

We model the joint process governing stock market returns indices in three CEECs, Russia and the UK using a tri-variate VAR-GARCH(1,1)-in-mean framework ${ }^{1}$. The model has the following specification:

$$
\mathbf{x}_{t}=\boldsymbol{\alpha}+\boldsymbol{\beta} \mathbf{x}_{t-1}+\gamma \mathbf{h}_{t-1}+\delta \mathbf{f}_{t-1}+\mathbf{u}_{t}
$$

where $\mathbf{x}_{t}=\left(\right.$ CEEC Country, Russia,$\left.U K_{t}\right)$ and $\mathbf{h}_{t-1}=\left(h_{1 t-1}, h_{2 t-1}, h_{3 t-1}\right)$ is the GARCH-in-mean vector. We control for monetary policy shocks by including in the mean equation the domestic 90-day Treasury Bill interest rate. Furthermore, exogenous shocks measured by US stock market returns, $\mathbf{f}_{t-1}=\left(\right.$ T Bill Interest $_{t-1}$, us ret t $\left._{t-1}\right)$, are also included as a proxy for market globalisation, enabling us to distinguish between worldwide and regionspecific developments driving financial integration. The residual vector $\mathbf{u}_{t}=\left(e_{1, t}, e_{2, t}, e_{3, t}\right)$ is tri-variate and normally distributed $\mathbf{u}_{t} \mid I_{t-1} \sim\left(\mathbf{0}, H_{t}\right)$ with its corresponding conditional variance covariance matrix given by:

$$
H_{t}=\left[\begin{array}{lll}
h_{11 t} & h_{12 t} & h_{13 t} \\
h_{12 t} & h_{22 t} & h_{23 t} \\
h_{13 t} & h_{23 t} & h_{33 t}
\end{array}\right]
$$

The parameter vector of the mean return equation (1) is defined by the constant $\boldsymbol{\alpha}=$ $\left(\alpha_{1}, \alpha_{2}, \alpha_{3}\right)$ and the autoregressive term, $\boldsymbol{\beta}=\left(\beta_{11}, \beta_{12}, \beta_{13}\left|\beta_{21}, \beta_{22}, \beta_{23}\right| \beta_{31}, \beta_{32}, \beta_{33}\right)$. Furthermore, $\gamma=\left(\gamma_{11}, \gamma_{12}, \gamma_{13}|0,0,0| 0,0,0\right)$ and $\boldsymbol{\delta}=\left(\delta_{12}, \delta_{13}|0,0| 0,0\right)$ are respectively the GARCH-in-mean and the exogenous parameters that appear in the first equation only. The parameter matrices for the variance Equation (2) are defined as $C_{0}$, which is restricted to be upper triangular, and two unrestricted matrices $A_{11}$ and $G_{11}$. In order to account for the possible effects of the introduction of the euro (January 1999) and of the EU accession (May 2004), we include two dummy variables (denoted by ${ }^{*}$ and ${ }^{* *}$ respectively). Therefore, the second moment will take the following form ${ }^{2}$ :

$$
H_{t}=C_{0}^{\prime} C_{0}+A_{11}^{\prime}\left[\begin{array}{lll}
e_{1, t-1}^{2} & e_{2, t-1} e_{1, t-1} & e_{3, t-1} e_{1, t-1} \\
e_{1, t-1} e_{2, t-1} & e_{2, t-1}^{2} & e_{3, t-1} e_{2, t-1} \\
e_{1, t-1} e_{3, t-1} & e_{2, t-1} e_{3, t-1} & e_{3, t-1}^{2}
\end{array}\right] A_{11}+G_{11}^{\prime} H_{t-1} G_{11}
$$

\footnotetext{
${ }^{1}$ The model is based on the GARCH(1,1)-BEKK representation proposed by Engle and Kroner (1995).

${ }^{2}$ Parameters $\left(a_{21}\right)$ and $\left(a_{31}\right)$ in Equation (3) measure the causality effect (interdependence), whereas $\left(a_{21}+a_{21}^{*}\right)$ and $\left(a_{31}+a_{31}^{*}\right)$ the possible effect of the introduction of the euro (contagion). Furthermore, $\left(a_{21}+a_{21}^{* *}\right)$ and $\left(a_{31}+a_{31}^{* *}\right)$ measure the effect of the EU accession (contagion).
} 
where

$$
A_{11}=\left[\begin{array}{lll}
a_{11} & a_{12} & a_{13} \\
a_{21}+a_{21}^{*}+a_{21}^{* *} & a_{22} & a_{23} \\
a_{31}+a_{31}^{*}+a_{31}^{* *} & a_{32} & a_{33}
\end{array}\right] ; G_{11}=\left[\begin{array}{lll}
g_{11} & g_{12} & g_{13} \\
g_{21}+g_{21}^{*}+g_{21}^{* *} & g_{22} & g_{23} \\
g_{31}+g_{31}^{*}+g_{31}^{* *} & g_{32} & g_{33}
\end{array}\right]
$$

Equation (3) models the dynamic process of $H_{t}$ as a linear function of its own past values $H_{t-1}$ and past values of the squared innovations $\left(e_{1, t-1}^{2}, e_{2, t-1}^{2}, e_{3, t-1}^{2}\right)$. The BEKK model guarantees by construction that the covariance matrix in the system is positive definite. Furthermore, conditional correlations between equity markets of the three CEECs considered (Czech Republic, Hungary and Poland) and Russia and the UK will be given respectively by:

$$
\boldsymbol{\rho}_{12, t}=h_{12, t} / \sqrt{h_{11, t}} \sqrt{h_{22, t}} \text { and } \boldsymbol{\rho}_{13, t}=h_{13, t} / \sqrt{h_{11, t}} \sqrt{h_{33, t}}
$$

Given a sample of $T$ observations, a vector of unknown parameters $\theta$ and a $3 \times 1$ vector of variables $\mathbf{x}_{t}$, the conditional density function for model (1) is:

$$
f\left(\mathbf{x}_{t} \mid I_{t-1} ; \theta\right)=(2 \pi)^{-1}\left|H_{t}\right|^{-1 / 2} \exp \left(-\frac{\mathbf{u}_{t}^{\prime}\left(H_{t}^{-1}\right) \mathbf{u}_{t}}{2}\right)
$$

The log-likelihood function is:

$$
L=\sum_{t=1}^{T} \log f\left(\mathbf{x}_{t} \mid I_{t-1} ; \theta\right)
$$

where $\theta$ is the vector of unknown parameters. Standard errors are calculated using the quasi-maximum likelihood methods of Bollerslev and Wooldridge (1992), which is robust to the distribution of the underlying residuals.

\section{Empirical results}

We use weekly data (from Datastream) for three CEEC countries (Czech Republic, Hungary and Poland) as well as the UK and Russia. Furthermore, we control for monetary policy and stock market globalisation using domestic interest rates (90-day Treasury Bill interest rate) and a proxy for the global stock market index (US stock market index) over the period $12 / 1 / 1996-12 / 3 / 2008$, for a total of 614 observations ${ }^{3}$. The three CEECs under investigation

\footnotetext{
${ }^{3}$ Although the stock market indices of the CEECs include a wide variety of sectors, the energy, banking, mining, pharmaceutical and telecom industries dominate them. In particular, the main components by country are as follows: for the Czech Republic, energy (20\%), banking (25\%) and telecom (18\%); for Hungary, pharmaceutical (35\%), chemical (15\%) and banking (11\%); for Poland, energy (16\%), banking (22\%) and
} 
have the biggest financial markets by market capitalisation in the region. We define weekly returns as logarithmic differences of stock indices. Weekly data are chosen to overcome the problem of asynchronous trading (with the US) which is present in the case of daily data and would bias some of the results. In order to test the adequacy of the models, Ljung- Box portmanteau tests were performed on the standardised and squared residuals. Overall, the results indicate that the VAR-GARCH(1,1)-in-mean specification captures satisfactorily the persistence in returns and squared returns of all the series considered. Cross-market dependence in the conditional mean and variance vary in magnitude and sign across countries. Note that the sign in cross-market volatilities are not relevant. The estimated VAR-GARCH(1,1)-in-mean model with associated robust standard errors and likelihood function values are presented in Tables 1-3.

\section{Please Insert Tables 1-3 and Figure 1 about here}

We select the optimal lag length of the mean equation using the Schwarz information criterion. The parameter estimates for the conditional means suggest statistically significant spillovers-in-mean at the standard 5\% significance level. In particular, spillovers originating from Russia are bigger than those from the UK $\left(\beta_{13}\left\langle\beta_{12}\right)\right.$ for all countries considered.

Concerning the conditional variance equations, the estimated "own-market" coefficients are statistically significant and the estimates of $g_{11}$ suggest a high degree of persistence. The VAR-GARCH(1,1)-in-mean framework also allows us to analyse by means of Wald tests on the relevant parameters the validity of several other hypotheses, specifically (i) the presence of spillovers from Russian $\left(a_{21}=g_{21}=0\right)$ and UK $\left(a_{31}=g_{31}=0\right)$ stock return volatilities to the CEEC ones (interdependence); (ii) the effect of Russian $\left(a_{21}^{*}=g_{21}^{*}=0\right)$ and UK $\left(a_{31}^{*}=g_{31}^{*}=0\right)$ stock return volatilities on the CEEC ones after the introduction of the euro (contagion), and (iii) the effect of Russian $\left(a_{21}^{* *}=g_{21}^{* *}=0\right)$ and UK $\left(a_{31}^{* *}=g_{31}^{* *}=0\right)$ stock return volatilities on the CEEC ones after the EU accession (contagion). Therefore, volatility spillovers from Russia and the UK to the CEEC markets are reflected in the parameters $a_{21}$ and $g_{21}$, and $a_{31}$ and $g_{31}$, respectively; $a_{21}^{*}$ and $g_{21}^{*}$, and $a_{31}^{*}$ and $g_{31}^{*}$ capture shifts in these parameters after the introduction of the euro, whereas $a_{21}^{* *}$ and $g_{21}^{* *}$, and $a_{31}^{* *}$ and $g_{31}^{* *}$ capture shifts after the EU accession date, both of which can be seen as contagion.

telecom (11\%); for Russia, energy (40\%), banking (25\%) and telecom (9\%); finally, for UK, energy (21\%), banking (18\%), mining (11\%) and telecom (8\%). In particular, for Czech Republic, energy (20\%), banking (25\%) and telecom (18\%); for Hungary, pharmaceutical (35\%), chemical (15\%) and banking (11\%); for Poland, energy (16\%), banking (22\%) and telecom (11\%); Russia, energy (40\%), banking (25\%) and telecom (9\%); and finally for UK, energy (21\%), banking (18\%), mining (11\%) and telecom (8\%). 
The results reported in Tables 1-3 suggest the following. First, when considering the effect of Russian stock market return volatilities on the CEEC ones we observe significant spillover effects (i.e., interdependence). The coefficient (in absolute value) is largest in the case of Hungary, being equal to -0.0465 . The spillover effects increase after the introduction of the euro $\left(a_{21}+a_{21}^{*}\right)$, in particular for Poland, the corresponding coefficient increasing to 0.101. The effects of EU accession $\left(a_{21}+a_{21}^{* *}\right)$ are less clear, the coefficients increasing (in absolute value) in the cases of the Czech Republic and Hungary and decreasing in the case of Poland to $-0.1521,-0.0869$ and -0.0125 respectively (recall that increases in the absolute size of the estimated parameters represent evidence of contagion).

Concerning the effect of UK stock market return volatility on the CEEC ones, we also find evidence of significant spillovers (interdependence). In particular, in the case of Hungary these are much stronger compared to those from Russia, the relevant coefficient now being equal to 0.7414 . The effects of the introduction of the euro on spillovers $\left(a_{31}+a_{31}^{*}\right)$ are mixed (since the UK is a EU member but is not part of the euro zone, it is not clear what the prior should be), with an increase in the coefficient in the case of the Czech Republic (0.7695) and a decrease for Hungary and Poland (0.0953 and -0.3263 respectively). On the contrary, the effects of EU accession $\left(a_{31}+a_{31}^{* *}\right)$ are positive in all cases, with the estimated coefficients being equal to $0.8537,0.9360$ and 0.7324 for the Czech Republic, Hungary and Poland respectively. Again, these estimates indicate that contagion occurs.

Overall, we find that spillovers running from the UK are bigger than those originating from Russia $\left(a_{21}\left\langle a_{31}\right)\right.$ for all countries considered. At the same time, there is no evidence of volatility spillovers from the CEEC towards the Russian and UK stock markets ${ }^{4}$. Also, the exogenous variables considered are statistically significant for all three CEECs, indicating a negative $\delta_{12}$ (TBill interest rate) and positive $\delta_{13}$ (US stock returns) effect, as we would expect.

Finally, there is also evidence of integration (interdependence), as shown by the conditional correlations of these markets (Figure 1) derived from the BEKK-GARCH model. In particular, the correlations are positive over the whole sample. The marked increase in all pairwise correlations (but for Hungary) after 2004 both with Russia and the UK once again suggests a change in the transmission mechanism and can be interpreted as contagion ${ }^{5}$. Interestingly, the degree of integration is bigger with the UK than with Russia $\left(\boldsymbol{\rho}_{12, t}\left\langle\boldsymbol{\rho}_{13, t}\right)\right.$ for all three countries.

\footnotetext{
${ }^{4}$ These results, not significant at the standard 5\% significance level, are not reported.

${ }^{5}$ Another explanation of increasing linkages could be the dual listing of (mostly) energy, telecom and banking companies (see Hanousek and Kocenda, 2009).
} 


\section{Conclusions}

This paper has analysed financial linkages between three CEEC countries (Czech Republic, Hungary and Poland) and both the UK and Russia using a VAR-GARCH(1,1)-in-mean framework. The estimated model has allowed us to distinguish between interdependence and contagion in the form of possible effects of the introduction of the euro and EU accession on existing volatility spillovers. By controlling for market globalisation, we are also able to attribute changes in the degree of integration to region-specific rather than worldwide factors. The analysis provides a number of interesting insights. In particular, it suggests that there is significant co-movement (interdependence) between stock markets in the three CEEC countries considered and both the UK and Russian ones. More in detail, spillovers from Russia and the UK influence the dynamics of the conditional variance of returns in the three CEEC stock markets examined, but there are no volatility spillovers in the opposite direction. These results differ to some extent from those of Egert and Kocenda (2007), who (using intraday data) find evidence of volatility spillovers from the CEEC markets to the EU ones, but are in line with their finding of no spillovers in mean in the same direction. Interestingly, there is evidence of shifts in the spillover parameters after the introduction of the euro and EU accession. These findings are consistent with earlier research indicating that volatility spillovers are significant mainly from dominant to smaller markets, with the magnitude of such effects increasing as a result of an increase in the volatility of dominant markets (Janakiramanan and Lamba, 1998; Hamao et al., 1990).

Furthermore, CEEC stock markets have become even more correlated with the UK after the EU accession (consistently with Harrison and Moore, 2009, but not Gilmore et al., 2008), suggesting contagion and a higher degree of integration associated with EU membership. The effects of the introduction of the euro have instead been mixed. The UK being a EU member but not having joined the common currency, it is not clear what should be expected. Cappiello et al. (2006) found increasing co-movement of the three CEECs considered here with the euro zone itself in the process towards EU accession, whilst Savva and Aslanidis (2009) estimated that the conditional correlation increased between 1997 and 2008 for the Czech Republic and Poland but remained unchanged for Hungary ${ }^{6}$.

It is noteworthy that our finding of sizeable and statistically significant dynamic correlations at a weekly frequency is in contrast to the evidence reported by Egert and Kocenda (2009) for the EU markets on the basis of intra-day data: at such a frequency a high degree of synchronisation is found between "old" EU markets, whilst the "new" ones appear to be

\footnotetext{
${ }^{6}$ Increasing correlations with developed markets were also reported by Gelos and Sahay (2000) and ChelleySteely (2005).
} 
totally disconnected.

Our results have important implications for portfolio management strategies. First, hedge funds and institutional investors should be cautious in considering CEEC stock returns for diversification purposes when forming a portfolio including Russian and UK stock returns as well. Second, it appears that the EU accession has further reduced the benefits of portfolio diversification, since it has resulted in a much higher degree of integration, in particular with the UK. Including all the CEEC stock markets in the analysis would provide further evidence on the possible benefits of portfolio diversification. The factors behind stock market integration could also be investigated (for instance, the role of macroeconomic announcements has been analysed by Hanousek and Kocenda, 2009). These constitute interesting topics for future research, but are beyond the scope of the present study. 


\section{References}

[1] Bekaert, G., Harvey, C.R., Ng, A. (2005), "Market integration and contagion", Journal of Business 78, 1, 39-69.

[2] Bohl, M.T. Gootschalk, K. and R. Pal (2006), "Institutional investors and stock market efficiency: The case of the January anomaly", MPRA Paper no. 677.

[3] Bollerslev, T.P. and J.M. Wooldridge (1992), "Quasi-maximum likelihood estimation and inference in dynamic models with time-varying covariances", Econometric Review, $11,143-172$.

[4] Caporale, G.M, Cipollini, A., Spagnolo, N. (2005), "Testing for contagion: a conditional correlation analysis", Journal of Empirical Finance, 12, 3, 476-489.

[5] Cappiello, L., Gerard, B., Kadareja, A. and S. Manganelli (2006), "Financial integration of new EU member states", Working Paper no. 683, European Central Bank, Frankfurt.

[6] Chelley-Steely, P.L. (2005), "Modeling equity market integration using smooth transition analysis: a study of Eastern European stock markets", Journal of International Money and Finance, 24, 818-831.

[7] De Pietri, M., Sardena, T. and L. Zicchino (2009), "Co-movements between bond markets in euro area and Eastern European countries: an identification through hetereskedasticity", paper presented at the CICM Conference on "20 Years of Transition in Central and Eastern Europe: Money, Banking and Financial Markets", London Metropolitan Business School, London, 17-18 September 2009.

[8] Engle, R.F., and K.F. Kroner (1995), Multivariate simultaneous generalized ARCH, Econometric Theory, 11, 122-150.

[9] Engle, R.F. and R. Susmel (1993), "Common volatility in international equity markets", Journal of Business and Economic Statistics, 11, 2, 167-176.

[10] Egert, B. and E. Kocenda (2007), "Interdependence between Eastern and Western European stock markets: evidence from intraday data", Economic Systems, 31, 184-203.

[11] Egert, B., and E. Kočenda (2009), "Time-Varying Synchronization of the European Stock Markets", Empirical Economics, forthcoming.

[12] Felices, G., Grisse, C. and J. Yang (2009), "International financial transmission: emerging and mature markets", Bank of England WP no. 373. 
[13] Forbes, K.J., and R. Rigobon (2002), "No contagion, only interdependence: measuring stock market co-movements", Journal of Finance, 57, 5, 2223-2261.

[14] Francis, B.B. and L.L. Leachman (1998), "Superexogeneity and the dynamic linkages among international equity markets", Journal of International Money and Finance, 17, 475-494.

[15] Gelos, G. and R. Sahay (2000), "Financial market spillovers in transition economies", IMF WP/00/71.

[16] Gilmore, C.G. and G.M. McManus (2003), "International portfolio diversification: US and Central European equity markets", Emerging Markets Review, 3, 1, 69-83.

[17] Gilmore, C.G. and G.M. McManus (2003), "Bilateral and multilateral cointegration properties between the German and Central European equity markets", Studies in Economics and Finance, 21, 40-53.

[18] Gilmore, C.G., Lucey, B.M. and G.M. McCanus (2008), "The dynamics of Central European equity market co-movements", Quarterly Review of Economics and Finance, 48, 605-622.

[19] Hamao,Y., Masulis, R.W., Ng, V. (1990), "Correlations in price changes and volatility across international stock markets". Review of Financial Studies, 3, 2, 281-307.

[20] Hanousek, J., Kocenda, E. and A.M. Kutan (2009), "The reaction of asset prices to macroeconomic announcements in new EU markets: evidence from intraday data", Journal of Financial Stability, 5, 2, 199-219.

[21] Hanousek, J. and E. Kocenda (2009), "Intraday price discovery in emerging European stock markets", CERGE-EI Working Paper no. 382, also presented at the CICM Conference on "20 Years of Transition in Central and Eastern Europe: Money, Banking and Financial Markets", London Metropolitan Business School, London, 17-18 September 2009.

[22] Harrison, B. and W. Moore (2009), "Non-linear stock market comovement in Central and East European countries", paper presented at the CICM Conference on "20 Years of Transition in Central and Eastern Europe: Money, Banking and Financial Markets", London Metropolitan Business School, London, 17-18 September 2009.

[23] International Monetary Fund (2005), Direction of Trade Statistics Quarterly: June 2005, Washington DC, International Monetary Fund. 
[24] Janakiramanan, S., Lamba, A.S. (1998), "An empirical examination of linkages between Pacific-Basin stock markets". Journal of International Financial Markets Institutions and Money, 8, 155-173.

[25] Jochum, C., Kirchgasser, G. and M. Platek (1999), "A long run relationship between Eastern European stock markets? Cointegration and the 1997/98 crisis in emerging markets", Weltwirtschafliches Archiv, 135, 455-479.

[26] Kasa, K. (1992), "Common stochastic trends in the international stock markets", Journal of Monetary Economics, 29, 95-124.

[27] Koedijk, K.C.G., Campbell, R.A.J. and P. Kofman (2002), "Increased correlation in bear markets", Financial Analysts Journal, 58, 87-94.

[28] Linne, T. (1998), "The integration of the Central and Eastern European equity markets into the international capital markets: a cointegration analysis", Working Paper, Institut fur Wirtschaftsforschung, Halle.

[29] Ljung, G.M. and G.E.P. Box (1978), "On a measure of lack of fit in time series models", Biometrika 65, 297-303.

[30] Longin, F. and B. Solnik (1995), "Is the correlation in international equity returns constant: 1960-1990?", Journal of International Money and Finance, 14, 3-26.

[31] MacDonald, R. (2001), "Transformation of external shocks and capital market integration" in M. Schroder (ed.), The New Capital Markets in Central and Eastern Europe, 210-245, The Centre for European Economic Research, Springer Verlag.

[32] Mijaljek, D. (2009), "The spread of the financial crisis to Central and Eastern Europe: evidence from BIS data", paper presented at the CICM Conference on "20 Years of Transition in Central and Eastern Europe: Money, Banking and Financial Markets", London Metropolitan Business School, London, 17-18 September 2009.

[33] Ng, A. (2000), "Volatility spillover effects from Japan and the US to the Pacific basin", Journal of International Money and Finance, 19, 207-233.

[34] Richards, A. (1995), "Comovement in national stock market returns: evidence of predictability, but not cointegration", Journal of Monetary Economics, 36, 455-479.

[35] Rigobon, R. (2003), "Identification through heteroskedasticity", Review of Economics and Statistics, 85, 4, 777-792. 
[36] Savva, C.S. and N. Aslanidis (2009), "Stock market integration between new EU member states and the Euro-zone", Empirical Economics, published online 1 September 2009.

[37] Scheicher, M. (2001), "The comovements of stock markets in Hungary, Poland and the Czech Republic", International Journal of Finance and Economics, 6, 27-39.

[38] Serwa, D. and M.T. Bohl (2005), "Financial contagion vulnerability and resistance: a comparison of European stock markets", Economic Systems, 29, 3, 344-362.

[39] Syriopoulos, T. (2007), "Dynamic linkages between emerging European and developed stock markets: has the EMU any impact?", International Review of Financial Analysis, $16,41-60$.

[40] Verchenko, O. (2000), "Potential for portfolio diversification across Eastern European stock markets", MA dissertation in Economics, National University Kiev-Mohyla Academy.

[41] Voronkova, S. (2004), "Equity market integration in Central European emerging markets: a cointegration analysis with shifting regimes", International Review of Financial Analysis, 13, 633-647. 
TABLE 1: Estimated VAR-GARCH(1,1)-M model

Czech Republic

\begin{tabular}{llllll}
\hline \hline & Coeff. & S.E. & Coeff. & S.E. \\
\multicolumn{5}{c}{ Conditional Mean Equation } \\
\hline$\alpha_{1}$ & 0.0142 & $(0.0066)$ & $\beta_{11}$ & 0.0055 & $(0.0261)$ \\
$\alpha_{2}$ & 0.0067 & $(0.0024)$ & $\beta_{12}$ & 0.0323 & $(0.0145)$ \\
$\alpha_{3}$ & 0.0019 & $(0.0007)$ & $\beta_{13}$ & 0.0096 & $(0.0051)$ \\
& & & $\beta_{22}$ & 0.0346 & $(0.0184)$ \\
$\gamma_{11}$ & 0.3622 & $(0.0256)$ & $\beta_{33}$ & 0.1341 & $(0.0426)$ \\
$\gamma_{12}$ & 0.0419 & $(0.0249)$ & $\delta_{12}$ & -0.0003 & $(0.0001)$ \\
$\gamma_{13}$ & 0.1082 & $(0.0876)$ & $\delta_{13}$ & 0.1141 & $(0.0490)$
\end{tabular}

Conditional Variance Equation

\begin{tabular}{|c|c|c|c|c|c|}
\hline$c_{11}$ & 0.0159 & $(0.0067)$ & & & \\
\hline$c_{12}$ & 0.0053 & $(0.0027)$ & & & \\
\hline$c_{22}$ & 0.0007 & $(0.0023)$ & & & \\
\hline$g_{11}$ & 0.6488 & $(0.2625)$ & $a_{11}$ & 0.1632 & $(0.8163)$ \\
\hline$g_{21}$ & -0.1127 & $(0.0281)$ & $a_{21}$ & 0.0139 & $(0.0069)$ \\
\hline$g_{21}^{*}$ & 0.0525 & $(0.0218)$ & $a_{21}^{*}$ & 0.2126 & $(0.0547)$ \\
\hline$g_{21}^{* *}$ & -0.1763 & $(0.0829)$ & $a_{21}^{* *}$ & -0.1660 & $(0.0584)$ \\
\hline$g_{12}$ & & & $a_{12}$ & & \\
\hline$g_{13}$ & & & $a_{13}$ & & \\
\hline$g_{22}$ & -0.9778 & $(0.0141)$ & $a_{22}$ & 0.1871 & $(0.0601)$ \\
\hline$g_{31}$ & 0.3325 & $(0.1691)$ & $a_{31}$ & 0.4328 & $(0.2154)$ \\
\hline$g_{31}^{*}$ & -0.2320 & $(0.0773)$ & $a_{31}^{*}$ & 0.3367 & $(0.2843)$ \\
\hline$g_{31}^{* *}$ & 0.0392 & $(0.0183)$ & $a_{31}^{* *}$ & 0.4209 & $(0.1483)$ \\
\hline$g_{33}$ & 0.9420 & $(0.0517)$ & $a_{33}$ & 0.3728 & $(0.1742)$ \\
\hline
\end{tabular}

LogLik $\quad 5421.71$

$$
\begin{array}{rrrrrr}
L B_{A,(10)} & 10.7577 & L B_{\text {Russia },(10)} & 9.9326 & L B_{U K,(10)} & 6.3864 \\
L B_{A,(10)}^{2} & 9.9749 & L B_{\text {Russia },(10)}^{2} & 10.4019 & L B_{U K,(10)}^{2} & 5.8260 \\
\hline
\end{array}
$$

Note: Standard errors (S.E.) are calculated using the quasi-maximum likelihood method of Bollerslev and Wooldridge (1992), which is robust to the distribution of the underlying residuals. Parameters not statistically 
significant at the $5 \%$ level are not reported. $\mathrm{LB}_{A(10)}$ and $\mathrm{LB}_{B(10)}^{2}$ are respectively the Ljung-Box test (1978) of significance of autocorrelations of five lags in the standardized and standardized squared residuals for country A (Czech Republic, Hungary, Poland), UK and Russia. The parameters $\beta_{12}, a_{21}$ and $g_{21}$ measure the causality effect running from Russia to country $\mathrm{A}$ whereas parameters $\beta_{13}, a_{31}$ and $g_{31}$ measure the causality effect running from the UK to country A. The covariance stationarity condition is satisfied by all the estimated models, all the eigenvalues of $A_{11} \otimes A_{11}+G_{11} \otimes G_{11}$ being less than one in modulus. Note that in the conditional variance equation the sign of the parameters is not relevant. 
TABLE 2: Estimated VAR-GARCH(1,1)-M model

Hungary

\begin{tabular}{llllll}
\hline \hline & Coeff. & S.E. & Coeff. & S.E. \\
\multicolumn{5}{c}{ Conditional Mean Equation } \\
\hline$\alpha_{1}$ & 0.0116 & $(0.0054)$ & $\beta_{11}$ & 0.0493 & $(0.0218)$ \\
$\alpha_{2}$ & 0.0057 & $(0.0026)$ & $\beta_{12}$ & 0.0333 & $(0.0169)$ \\
$\alpha_{3}$ & 0.0020 & $(0.0007)$ & $\beta_{13}$ & 0.0137 & $(0.0050)$ \\
& & & $\beta_{22}$ & 0.0093 & $(0.0043)$ \\
$\gamma_{11}$ & 0.8848 & $(0.4229)$ & $\beta_{33}$ & 0.1138 & $(0.0366)$ \\
$\gamma_{12}$ & & & $\delta_{12}$ & -0.0013 & $(0.0003)$ \\
$\gamma_{13}$ & & & $\delta_{13}$ & 0.1355 & $(0.0648)$
\end{tabular}

Conditional Variance Equation

\begin{tabular}{|c|c|c|c|c|c|}
\hline$c_{11}$ & 0.0059 & $(0.0013)$ & & & \\
\hline$c_{12}$ & 0.0051 & $(0.0023)$ & & & \\
\hline$c_{22}$ & 0.0004 & $(0.0002)$ & & & \\
\hline$g_{11}$ & 0.9579 & $(0.0201)$ & $a_{11}$ & 0.0432 & $(0.0227)$ \\
\hline$g_{21}$ & -0.2296 & $(0.0806)$ & $a_{21}$ & -0.0465 & $(0.0206)$ \\
\hline$g_{21}^{*}$ & -0.0200 & $(0.0096)$ & $a_{21}^{*}$ & 0.1380 & $(0.0426)$ \\
\hline$g_{21}^{* *}$ & -0.2458 & $(0.0933)$ & $a_{21}^{* *}$ & -0.0404 & $(0.0199)$ \\
\hline$g_{12}$ & & & $a_{12}$ & & \\
\hline$g_{13}$ & & & $a_{13}$ & & \\
\hline$g_{22}$ & -0.9792 & $(0.0107)$ & $a_{22}$ & 0.1827 & $(0.0473)$ \\
\hline$g_{31}$ & -0.1712 & $(0.0831)$ & $a_{31}$ & 0.7414 & $(0.1834)$ \\
\hline$g_{31}^{*}$ & 0.1626 & $(0.0765)$ & $a_{31}^{*}$ & -0.6461 & $(0.1902)$ \\
\hline$g_{31}^{* *}$ & -0.0452 & $(0.0558)$ & $a_{31}^{* *}$ & 0.1946 & $(0.0929)$ \\
\hline$g_{33}$ & 0.9294 & $(0.0362)$ & $a_{33}$ & 0.4111 & $(0.1136)$ \\
\hline
\end{tabular}

LogLik $\quad 5357.15$

$\begin{array}{lrllll}L B_{A,(10)} & 2.5396 & L B_{\text {Russia,(10) }} & 7.3505 & L B_{U K,(10)} & 7.1575 \\ L B_{A,(10)}^{2} & 10.1848 & L B_{\text {Russia,(10) }}^{2} & 8.8561 & L B_{U K,(10)}^{2} & 6.6241\end{array}$

Note: See notes Table 1. 
TABLE 3: Estimated VAR-GARCH(1,1)-M model

Poland

\begin{tabular}{llllll}
\hline \hline & Coeff. & S.E. & Coeff. & S.E. \\
\multicolumn{5}{c}{ Conditional Mean Equation } \\
\hline$\alpha_{1}$ & 0.0090 & $(0.0049)$ & $\beta_{11}$ & 0.0537 & $(0.0215)$ \\
$\alpha_{2}$ & 0.0054 & $(0.0024)$ & $\beta_{12}$ & 0.0261 & $(0.0149)$ \\
$\alpha_{3}$ & 0.0013 & $(0.0006)$ & $\beta_{13}$ & 0.0051 & $(0.0018)$ \\
& & & $\beta_{22}$ & 0.0238 & $(0.0102)$ \\
$\gamma_{11}$ & 0.2886 & $(0.0917)$ & $\beta_{33}$ & 0.1173 & $(0.0443)$ \\
$\gamma_{12}$ & & & $\delta_{12}$ & -0.0004 & $(0.0002)$ \\
$\gamma_{13}$ & & & $\delta_{13}$ & 0.1595 & $(0.0702)$
\end{tabular}

Conditional Variance Equation

\begin{tabular}{lccccc}
\hline$c_{11}$ & 0.0033 & $(0.0016)$ & & & \\
$c_{12}$ & 0.0042 & $(0.0021)$ & & & \\
$c_{22}$ & 0.0002 & $(0.0001)$ & & & \\
$g_{11}$ & 0.9824 & $(0.0152)$ & $a_{11}$ & -0.0312 & $(0.0161)$ \\
$g_{21}$ & 0.0123 & $(0.0056)$ & $a_{21}$ & 0.0139 & $(0.0058)$ \\
$g_{21}^{*}$ & -0.0228 & $(0.0116)$ & $a_{21}^{*}$ & 0.1149 & $(0.0565)$ \\
$g_{21}^{* *}$ & 0.0105 & $(0.0048)$ & $a_{21}^{* *}$ & -0.0264 & $(0.0151)$ \\
$g_{12}$ & & & $a_{12}$ & & \\
$g_{13}$ & & & $a_{13}$ & & \\
$g_{22}$ & 0.9731 & $(0.0088)$ & $a_{22}$ & 0.2178 & $(0.0367)$ \\
$g_{31}$ & 0.0224 & $(0.0095)$ & $a_{31}$ & -0.4328 & $(0.2154)$ \\
$g_{31}^{*}$ & -0.0091 & $(0.0044)$ & $a_{31}^{*}$ & 0.1065 & $(0.0502)$ \\
$g_{31}^{* *}$ & -0.0641 & $(0.0315)$ & $a_{31}^{* *}$ & -0.2996 & $(0.1483)$ \\
$g_{33}$ & 0.9585 & $(0.0116)$ & $a_{33}$ & 0.3065 & $(0.0448)$
\end{tabular}

LogLik $\quad 5433.50$

\begin{tabular}{lrllll}
$L B_{A,(10)}$ & 4.5955 & $L B_{\text {Russia,(10) }}$ & 7.1558 & $L B_{U K,(10)}$ & 6.9865 \\
$L B_{A,(10)}^{2}$ & 10.0790 & $L B_{\text {Russia,(10) }}^{2}$ & 8.4944 & $L B_{U K,(10)}^{2}$ & 7.4002 \\
\hline
\end{tabular}

Note: See notes Table 1. 
Figure 1: Conditional Correlations
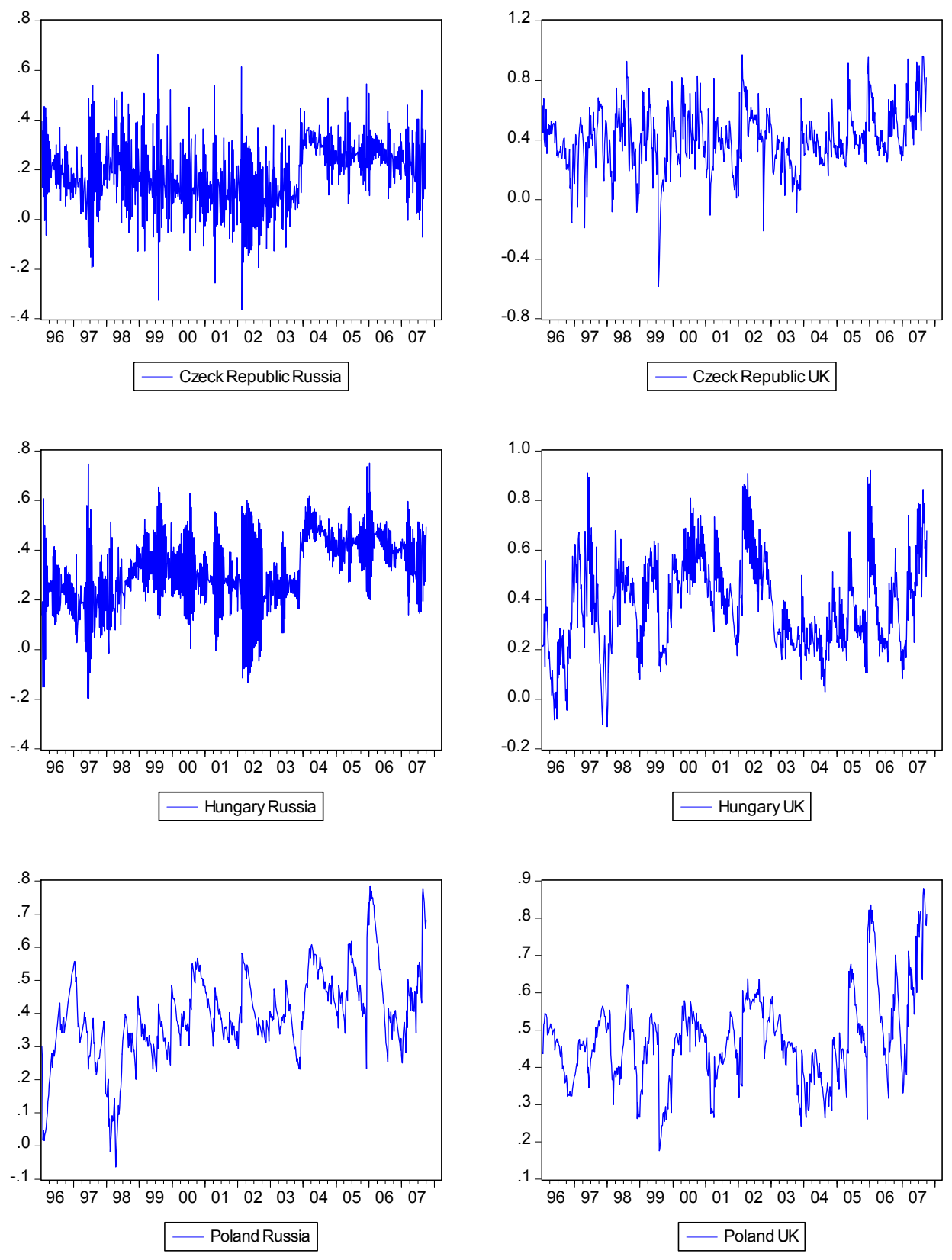